\title{
Macroeconomic problems and approach of the parametric control theory
}

\author{
Abdykappar Ashimov, Yuriy Borovskiy, Mukhit Onalbekov
}

\begin{abstract}
The paper presents the results of the approach to the solution of some macroeconomic problems of the regions (economic growth, reduction of regional disproportions, reduction of trade deficits and growth of the agricultural, forestry and fishery sector outputs) based on the developed Model and the approach of the parametric control theory. The developed Model is a global multi-country dynamic computable general equilibrium model (CGE model) which was built based on the known static CGE model Globe 1. The assessment of the fulfillment of the conditions for transferring the results of computational experiments based on the Model was carried out both by the approach of the parametric control theory and by other known methods. The problems of dynamic optimization that allow solving these macroeconomic problems at the level of individual countries, the economic union and the world economy were solved based on the Model, with methods of the parametric control theory. The greater benefit from joint concerted actions to solve the problems under consideration in comparison with the corresponding solutions of such problems at the level of individual regions (countries) is corroborated.
\end{abstract}

Keywords - Macroeconomic problem, Parametric control theory, CGE Model, testing of the Model

\section{Introduction}

Recurrent world crises underscore the need of adequate ways of addressing these pressing macroeconomic problems of countries and regions like economic growth, reducing regional disparities, reducing trade deficits, food problems, etc. These problems are widely discussed in the scientific literature (see, for example, [1-6]). But these and other available sources have a number of shortcomings: they do not consider the optimal coordinated state policy aimed at solving macroeconomic problems; the results of computational experiments on the solution of macroeconomic problems are not tested for the possibility of their transfer to practice.

Therefore, the development of adequate (tested for the possibility of practical implementation) measures of an optimal coordinated fiscal policy aimed at economic growth and other macroeconomic problems is an urgent task for both individual countries and economic unions and the world economy as a whole. It should be noted that theimplementation of joint concerted actions to address such problems should have a great benefit for each individual country as compared to the corresponding policies carried out at the country level. The parametric control theory developed by the authors [7] suggests approaches to assess the fulfillment of the conditions for transferring to practice the results of computational experiments on the mathematical models, as well as approaches to determine the optimal values of macroeconomic policy instruments by solving based on the mathematical models the corresponding optimization problems - parametric control problems. At the same time, it is necessary to apply global multi-country macroeconomic models to develop coordinated measures of such an optimal policy, conducted at the level of economic unions and the world economy.

In this paper, we present the results of the development of a global multi-country dynamic computable general equilibrium model (hereinafter referred to as the Model) based on the static CGE model Globe 1 [8]. The calibration results of the Model are presented based on the developed sets of matched Social Account Matrices (SAMs) of the Regions for the historical and forecast periods. The possibilities of the approach of the parametric control theory [7] are demonstrated as follows: on the estimation of the fulfillment of the conditions for transferring to practice the results of computational experiments based on the calibrated Model; on the solution of a number of formulated problems of parametric control. The benefits of coordinated actions for solving parametric control problems are justified. The parametric control problems under consideration are aimed at evaluating the optimal values of economic instruments that contribute to the solution of a number of macroeconomic problems, such as economic growth, reducing regional disparities, reducing trade deficits and increasing the output of the selected sector (Agriculture, Forestry and Fisheries) of the Regions. Let us note again, that the main difference between the approach of the parametric control theory and the approaches of other wellknown macroeconomic theories is the use of only such mathematical models for which the fulfillment of the conditions for transferring the results of computational experiments to practice with the help of a number of original and classical methods is assesse.

\section{The Model}

The dynamic Model is built by developing and binding to the data of the static CGE model Globe1 [8] as a result of the following basic steps.

1. Building of a conceptual description of the world economy.

2. The Model building in the GAMS environment [9] based on the built conceptual description and the Globe 1 model.

3. Selection of the composition of the Regions and Industries, the historical and forecasting periods of the Model calculation. 
Proc. of The Eighth Intl. Conf. On Advances In Economics, Social Science and Human Behaviour Study - ESSHBS 2018

4. Building the database of the Model's initial data (matrices of social accounts, coefficients of elasticity of substitution etc.)

\section{Binding the Model to the initial data.}

Further in this section we give some results of the indicated steps implementation.

\section{A. Conceptual description of the world economy for Model building}

Let us first list some background for a conceptual description.

The world economy is represented in the form of functioning of interacting agents of selected Regions of the world economy:

- Industries (Producers) of the Region consist of identical elementary agents-firms;

- Households of the Region consists of identical elementary agents - households;

- the Government of the Region (as a consumer) consists of identical elementary agents - state structures;

- Agent-Region Globe imports transport services and exports them to all Regions when each type of goods is imported from each Region to another.

We list below the main functions of these agents pricetakers.

Producer agent in its activities annually:

- produces one, corresponding to the name of the Industry, type of production (subject to the condition of minimizing the costs);

- produces gross value added (based on the use of factors as the labor and the capital of the households);

- exports a part of produces production (subject to the condition of maximizing the profits);

- imports intermediate productions from other Regions and consumes intermediate production;

- pays net tax payments to their Government.

Producer agents solve following two pairs of the nested optimization problems:

- minimization costs for the purchase of the intermediate productions and GVA costs for a given production output;

- minimization costs for the purchase of the production factors at the given output of the final production;

- profit maximization from sales within the Region and beyond, at the given production output;

- profit maximization from exports to various Regions at the given level of production exports.

Household Agent in its activities annually:

- receives income from producers based on demand for the factors belonging to it from the producers of their region;

- consumes the productions from all the Regions (according to the solution of the problem of maximizing their utility functions under the budget constraints);

- perform savings in the form of investment products based on their income and consumption;

- pays net tax payments to their Government.

Government of each Region in its activities annually:

- determines the effective tax rates and receives income in the form of net tax revenue (including revenue from customs duties); spending);

consumes the final productions (Government

- performs savings in the form of investment products based on its income and expenses.

Industries, Household, and Government agents each year jointly solve the following optimization problems:

- determination of the optimal share of imports in the consumption of each type of production subject to minimum of costs of domestic and imported components of this production;

- determination of the optimal regional structure of each type of imported production subject to minimum of costs of this type of imported production.

The conceptual description of the "world economy" contains the statements of the abovementioned optimization problems with the corresponding first-order conditions, other equations describing the functions of the agents, balance ratios for prices and quantities (real indicators, measured in the prices of the producer), the internal balances in the accounts of the Government and the external balances of trade accounts.

The conceptual description uses the system of composite endogenous prices for all types of productions in each Region, including the prices of the buyers and sellers, the prices of the exporter and importer, and so on. The values of prices ensure the performance of the annual balance sheet ratios, while providing for the following:

- the equilibrium in factor (labor and capital) markets;

- the equilibrium in the markets for each type of production;

- bilateral current account balances for each pair of Regions; and

- the equilibrium of savings (Households, Governments) and their investments in the respective Regions' Industries.

The conceptual description in comparison with the basic version of Globe 1 [8] is developed by describing the following variables using dynamic equations: the technological coefficients of production functions for the GVS of all the Regions' industries, the supply of Factors (Labor and Capital) by the Households of the Regions.

\section{B. Model building in GAMS environment}

The mathematical Model, which is built based on its conceptual description, was obtained as a result of combining into the one system the equations describing: the first-order conditions of all agents' optimization tasks and other rules of agent activity (behavior), including equations describing the dynamics of technological coefficients of production functions and supply of factors (Labor and Capital). Balance and auxiliary equations are also included in the mathematical Model. Next, the closure of the Model was done: all variables were divided into two classes: endogenous and exogenous. At the same time, the exchange rates of all Regions' currencies were adopted as endogenous, that is, floating.

All equations of the mathematical model were loaded into the GAMS [9] environment as part of the main module of the Model. This module allows for the solution of the Model by finding the values of all endogenous variables of the Model for the given values of its exogenous variables.

The developed calibration module enables the calculation of all values of the Model based on the generated 
Proc. of The Eighth Intl. Conf. On Advances In Economics, Social Science and Human Behaviour Study - ESSHBS 2018 Copyright (C) Institute of Research Engineers and Doctors, USA. All rights reserved.

ISBN: 978-1-63248-156-6 doi: 10.15224/978-1-63248-156-6-18

database by means of special expressions. The calibration phase is carried out every time the Model is initiated. The solution of the Model's calibrated system of equations (Model Calculation) is performed through the software implemented in the GAMS integrated development environment using the built-in problem solver (PATH) [10].

\section{c. Selection of the composition of the Regions and Industries, historical and forecasting periods of Model's calculation}

The developed Model describes the dynamics of the interacting economies functioning of the following 9 Regions: Kazakhstan, other members of the Eurasian Economic Union (Russia, Belarus, Armenia, Kyrgyzstan), as well as the main trade partners of Kazakhstan (European Union (as one country), the USA, China and the Rest of the World (as one country).

The economy of each Model's Region is described by the following 16 productive sectors, which are the significant for the economy of Kazakhstan:

1 - Mining operations (except oil and gas);

2 - Mining of crude oil and gas;

3 - Metalworking production and mechanical engineering;

4 - Metallurgical production;

5 - Education, Health service, public administration;

6 - Production and transmission of electricity, gas and hot water;

7 - Manufacture of food products, beverages and tobacco;

8 - Professional, scientific and technical activities;

9 - Other industries;

10 - Other services;

11 - Agriculture, forestry and fisheries;

12 - Construction industry;

13 - Production of textiles, clothing, leather and related products:

14 - Financial service;

15 - Chemical and petrochemical industry;

16 - Transport

The Model calculation period (2004-2022) is determined by the available values of the SAM matrices from the GTAP database $(2004,2007,2011)$ and the horizon for the projections of the main macroeconomic indicators provided by the International Monetary Fund (2022).

\section{Database of the initial data and its link to the Model}

The core of the Model's database is the sets of matched social account matrices (SAM) of the Regions for each year under consideration (2004-2022). SAMs show how product flows (in monetary terms) and financial flows between Industries, Households, the Government, importers and exporters are distributed. The mentioned SAM sets for 2004, 2007 and 2011 were extracted using a special converter from the GTAP database [11]. It should be noted that in this database there are no data for the remaining years of the considered historical period 2004-2014. Therefore, for the years 2005-2006, 2008-2010 and 2012-2015 the required SAM sets were calculated using the developed Algorithm 1 based on available statistical sources containing input-output tables (see, for example, [12], indicators of mutual trade [13], using the base ratios calculated with the help of known SAMs for the nearest last year (2004, 2007 or 2011). For the forecast period (2016-2022), Algorithm 2 was used to calculate these SAM sets based on the following forecast indicators of the Regions provided by the World Bank [14]: GDP, Total investment, the volume of import of goods, the volume of import of services; the volume of exports of goods, the volume of exports of services, general government revenues, general government expenditure. In doing so, we used the baseline ratios calculated with the help of the obtained SAMs for 2015.

In addition to the obtained SAM sets, the database of the initial data of the Model includes the values of the elasticity coefficients of substitution of various factors in the production functions of the industries; the values of the replacement rates of various types of products in the functions of output industries, in aggregation functions that describe the consumption of agents, the parameters values of households utility functions, as well the initial values for the dynamic equations of the Model. These coefficients and parameters were obtained from the GTAP database [11] for 2004, 2007 and 2011 and then extrapolated to the remaining years of the Model calculation period (2004-2022).

Within the 5th step in the GAMS environment, the Model has been linked to the selected Regions, to economic sectors, to the calculation period, to the formed SAM database, and other values of the replacement rates and parameters indicated above. The results of calculating the obtained base scenario of the calibrated Model accurately reproduce the statistical and forecast data used in constructing the SAM sets for the Model's database of the initial data.

\section{The assessment of the fulfillment of the conditions for transferring the results of computational experiments}

The mentioned assessment was performed by three methods, the first two of which were proposed by the authors within the framework of the development of the parametric control theory.

\section{A. Assessing the stability of smooth mappings defined by the Model}

The availability of the stability properties of mapping $f: A \rightarrow B$, which transfers the values of the exogenous parameters $p \in A$ into the solutions (the values of endogenous variables), suggests preserving the qualitative properties with small (in some sense) changes of such a mapping. To assess the stability of the smooth mapping of the specified type, the authors proposed the corresponding set of numerical algorithms [15] for the cases of immersion, submersion, and submersion with a fold on the basis of the numerical evaluation of the fulfillment of its conditions. In the experiments, basic mappings of type $f: A \rightarrow B$ with $\operatorname{dim} A=5$ and $\operatorname{dim} B=9$ were considered, whereas the arguments of $f$ were taken the value-added tax rates of the five EAEU countries (Kazakhstan, Russia, Belarus, 
Armenia, and Kyrgyzstan) for 2015, and as the output variables of $f$ were taken the GDP values of all the 9 Regions of the Model for 2022. A five-dimensional box $A$ (with the center at the point $p=\left(p_{1}, \ldots, p_{5}\right)$, corresponding to the baseline values of the specified tax rates are distanced from the values $p_{i}$ to the value of $0.5 p_{i}$. It should be noted that the time to calculate the implemented mappings stability algorithms increases approximately exponentially with increasing the $\operatorname{dimension} \operatorname{dim} A$ of area $A$. This limits the use of this approach, so to obtain a reasonable calculation time the set of the most important factors used in the solution based on of the Model of specific problems for macroeconomic analysis and parametric control was selected.

The results of the specified numerical experiments demonstrated the absence of singular points of the $f$ mapping in $A$ box and the stability of this immersion.

\section{B. Estimation of stability indicators of mappings defined by the Model}

The $\beta_{f}(p, \alpha)$ stability indicator of the defined by the Model mapping $f: A \rightarrow B_{t}$ at the point $p \in A$ and for the selected positive $\alpha$ number is the diameter of the image (when $f$ mapping) of the ball with its radius $\alpha$ and with its center at the point $p$ (in relative terms). If for all the points $p \in A$ the numerical assessment of the $\beta_{f}(p)=$ $\lim _{\alpha \rightarrow 0} \beta_{f}(p, \alpha)$ value is uniformly close to zero, then the mapping $f$, defined by the tested Model is assessed on the set $A$ as continuously dependent on exogenous values.

In the experiments with the Model, as set $A$, a parallelepiped was considered centered at point $p$ corresponding to the baseline values of all the tax rates in all the Regions in 2004, whereas endogenous variables sets $B_{t}-$ GDP, exports, and imports of all the Regions of the Model for the fixed computational year $t$ (from 2004 to 2022).

As an example, Table I shows the calculated values of $\beta_{f}(p, 0.01)$ of the Model stability (in percent) for the base point $p$ and $\alpha=0.01$. All the specified in Table I values of the stability do not exceed 0.4536 , which characterizes the stability of the Model (in terms of the considered stability indicators) for calculations up to 2022 as sufficiently high. In particular, the acquired for 2004 value of the $\beta_{f}(p, 0.01)$ indicator means that the image of a sphere centered at the point $p$ (corresponding to the basic values of all the 2004 tax rates) and having the radius of 0.01 (in relative terms) in the calculation of the Model is transformed into a set with the diameter of 0.4536 (in relative terms) for the output variables values (GDP, exports, and imports of all the Regions in 2004). Various options of the calculated values of the limit indicators $\beta_{f}(p)$ were close enough to zero at $\alpha=0.0001$, which evaluates the tested mapping as a continuous one in box $A$.

TABLE I. VALUES OF STABILITY INDICATORS FOR THE BASIC CALCULATION OF THE MODEL

\begin{tabular}{|c|c|c|c|c|c|}
\hline \multicolumn{6}{|c|}{ Year } \\
\hline 2004 & 2005 & 2006 & 2007 & $2008-2015$ & $2016-2022$ \\
\hline 0.4536 & 0.0814 & 0.0098 & 0.0070 & 0.0001 & 0.0000 \\
\hline
\end{tabular}

\section{Implementation of counterfactual and forecast scenarios}

According to the well-known macroeconomic theory, the reduction of taxes levied on producers and consumers, as well as the increased state demand for consumer products will increase the country's output and GDP. As part of its testing, based on the Model counterfactual and forecast scenarios were calculated to assess the implementation of the provision of the theory. In particular, the scenario was performed featuring a $10 \%$ decrease in the effective tax rates of value added tax, tax on the Producers' income and 10\% increase in Government consumption in each EAEC country. The results of the calculation of this scenario demonstrated changes in GVA in each sector in the relevant country (ranging from $3.85 \%$ to $6.16 \%$ ) and increases in GDP in each Region ranging from $0.0279 \%$ in 2009 for global economy to $0.7715 \%$ in 2012 for EAEU, compared with the observed data.

The above results of the three test methods demonstrate the successful verification of the tested Model.

\section{Iv. Solutions to parametric control problems}

As part of the proposal of optimal measures to solve the problems of economic growth, growth of the selected sector's output (Agricultural, Forestry and Fisheries), reduction of trade deficits and reduction of disparities in regional development (for multi-country tasks), a number of parametric control problems were solved based on the Model. In these problems, the values of all uncontrolled exogenous variables of the Model correspond to the baseline forecast of these variables. Hereinafter indices $r=1, \ldots, 9$ correspond to the number of the Region: 1 - Kazakhstan, 2 Russia, 3 - Belarus, 4 - Armenia, 5 - Kyrgyzstan, 6 European Union, 7 - the USA, 8 - China, 9 - the Rest of the world. The value of $r=10$ corresponds to 5 countries of the EAEU, $r=11$ corresponds to the World Economy.

Statement of the problem $\operatorname{Pr}_{r}(r=1, \ldots, 11)$. To identify based on the Model the values of the control parameters $u(t)$ (effective tax rates for producers' revenues, sales and customs duty taxes differentiated by production and industry sector: shares of public spending for consumption) that provide the maximum value of the criterion $K_{r}(2)$ - (4) with constraints on regulatory instruments of $u(t) \in U(t)$ type and with restrictions (1) for some of the endogenous variables. Here for $t=2016, \ldots, 2022, U(t)-$ is a box with the center at the point of base values of $u(t)$ and with boundaries spaced at $\pm 10 \%$ of the baseline values.

For problems $\operatorname{Pr}_{r}(r=1, \ldots, 9)$ the $u(t)$ control parameters are the specified state policy instruments only for $r$-th Region, for the problem $P r_{10}$ - those of the five EAEU countries, and for the problem $P r_{11}$ - those of all of the nine Regions of the Model in the aggregate.

The restrictions for the endogenous variables of the Model in all the problems $\operatorname{Pr}_{r}$ look like:

$$
Q V A P_{r}(t) \geq \overline{Q V A P_{r}}(t) .
$$

Here: $r=1, \ldots, 9 ; t=2016, \ldots, 2022 ; Q V A P_{r}(t)$ is GDP per capita in the Region $r$; $\overline{Q V A P_{r}}(t)$ is the baseline value of 
this indicator. The fulfillment of the conditions (1) ensures that, in solving of its problem $P r_{r}$ by any Region (or by five countries forming the EAEU or by all of the Model's Regions), the values of $Q V A P_{r}(t)$ will not decrease (in comparison with the baseline forecast) not only in its Region, but also in all other Regions of the Model.

In each of the first nine formulated problems $\operatorname{Pr}_{r}$ $(r=1, \ldots, 9)$ an optimal fiscal policy aimed at economic growth and growth of agricultural output and a reduction in the trade deficit during 2016-2022 is assumed. In the Region $r$, while the behavior of the remaining Regions of the Model is characterized by the baseline values of the corresponding exogenous variables. Therefore, in these problems, the criterion $K_{r}$ is written as:

$$
\begin{gathered}
K_{r}=\sum_{t=2016}^{2022}\left(T Q V A_{r}(t)+\alpha_{T Q X A, r} T Q X A_{r}(t)-\right. \\
\left.\alpha_{K A P W O R, r} K A P W O R_{r}(t)\right) .
\end{gathered}
$$

Here $r=1, \ldots, 9 ; T Q V A_{r}(t)$ is GDP per capita rate, $T Q X A_{r}(t)$ is the rate of output of the following industry Agricultural, Forestry and Fisheries per, $\operatorname{KAPWOR}_{r}(t)$ trade deficit in goods and services in the Region $r$ in the year $t ; \alpha_{T Q X A, r}$ and $\alpha_{K A P W O R, r}-$ configurable coefficients.

In the $\operatorname{Pr}_{10}$ problem, it is planned to conduct a coordinated optimal fiscal policy within the framework of the five EAEU countries in 2016-2022, aimed at economic growth, the growth of the agricultural output in the EAEU $(r=10)$ and the approximation of GDP per capita value in each of the five countries of the EAEU to the corresponding values of the United States (the USA $(r=7)$ is the Region with the highest GDP per capita among all Regions according to the model calculation until 2022). Therefore, the criterion $K_{10}$ of the given problem is selected in the following form:

$$
\begin{gathered}
K_{10}= \\
\sum_{t=2016}^{2022}\left(T Q V A_{10}(t)+T Q X A_{10}(t)-\right. \\
\left.\alpha_{K A P W O R, 10} K A P W O R_{10}(t)\right) \\
-\frac{1}{\sum_{r=1}^{5} \varepsilon_{r}} \sum_{r=1}^{5}\left(\varepsilon_{r} \sum_{t=2016}^{2022}\left[\frac{Q V A P_{7}(t)-Q V A P_{r}(t)}{Q V A P_{7}(t)}\right]\right) .
\end{gathered}
$$

Here $\varepsilon_{r}$-weight number, $\varepsilon_{r}=0.1$ for medium-developed Regions (Kazakhstan and Russia), $\varepsilon_{r}=1$ for all other Regions - members of the EAEU.

In the problem $\operatorname{Pr}_{11}$ it is considered the hypothetical possibility of coordinated optimal fiscal policy within the framework of all Regions of the Model in 2016-2022, aimed at the global economic growth, the growth of world agricultural output, and the approximation of the GDP per capita values in each Region to the respective values in the United States. Therefore, the criterion $K_{11}$ of this problem was selected as follows:

$$
\begin{gathered}
K_{11}= \\
\sum_{t=2016}^{2022}\left(T Q V A_{11}(t)+T Q X A_{11}(t)-\right. \\
\left.\alpha_{K A P W O R, 11} K A P W O R_{11}(t)\right) \\
-\frac{1}{\sum_{r=1}^{9} \varepsilon_{r}} \sum_{r=1}^{9}\left(\varepsilon_{r} \sum_{t=2016}^{2022}\left[\frac{Q V A P_{7}(t)-Q V A P_{r}(t)}{Q V A P_{7}(t)}\right]\right) .
\end{gathered}
$$

Here $\varepsilon_{r}=0.1$ for $r \in\{1,2,6,8\} ; \varepsilon_{7}=0$ and $\varepsilon_{r}=1$ for all other $r$

The formulated problems $P r_{r}$ were solved with numerical method using the optimization algorithm provided by the GAMS iterative optimization algorithm NLPEC [16]. The results of their solution in the form of increments of the average value of GDP and increments of the average output of the industry. The agricultural, forestry and fisheries of the Regions for 2016-2022 (per capita, in percent relative to the baseline scenario) are shown in Tables II and III, respectively.

The obtained optimal values of economic policy instruments of the mentioned above parametric control problems were tested for the possibility of their practical implementation as follows. The scenario options of the calibrated Model for the specified optimum values of the tools were tested by the three methods referred to in Section III. In all cases, the results were obtained similar to the above mentioned specified in Section III for the baseline scenario, namely:

- Permissible values of estimates of stability indicators.

- Absence of singular points of the considered mappings in their appropriate domains and the stability of these mappings.

- Coincidence of the results of the 2013-2018 forecast scenarios to the main provisions of the macroeconomic theory.

Analysis of bold type numbers in each column of Tables II and III shows that within problems $\operatorname{Pr}_{r},(r=1, \ldots, 11)$, the approach of parametric control at the level of all Regions (the problem $P r_{11}$ ), as well as at the level of the five countries of the EAEU (the problem $P r_{10}$ ), mostly gives greater effects for separate Region in comparison with parametric control at the level of separate Region (problems $\left.\operatorname{Pr}_{r}, r=1, \ldots, 9\right)$.

Additionally, as a result of solving the problem $\operatorname{Pr}_{11}$ the alignment of regions' economic development was achieved, characterized by a decrease in the ratio of maximum to minimum GDP per capita among all Regions by $5.91 \%$ in 2022 compared to the non-regulated option; by $5.27 \%$ in 2022 compared to 2015. There was also an increase in GDP per capita in 2022 compared to 2015 by $31.42 \%, 34.75 \%$ and $22.91 \%$ respectively for Kyrgyzstan, Armenia, the Rest of the world (less developed regions).

In general, as a result of solving the problem $P r_{11}$, the GDP growth per capita in 2022 was $1.38 \%$, and the growth of the output per capita of the following industries agriculture, forestry and fisheries is $7.92 \%$ compared with the corresponding baseline forecasts. GDP growth per capita in 2022 is $24.83 \%$, and the growth in output per capita of the sectors - agriculture, forestry and fisheries in 2022 is $41.38 \%$ compared with the corresponding base values of 2015. Also, the solution of each problem $\operatorname{Pr}_{r}(r=1, \ldots, 9)$ contributed to a reduction in the range of $0.05-3.36 \%$ of trade deficits in goods and services in the Regions.

The analysis of the presented results of the solutions of the problems $P r_{r}$ and the results of the corresponding tests shows the high potential of the parametric control approach for developing recommendations on the agreed optimal state 
Proc. of The Eighth Intl. Conf. On Advances In Economics, Social Science and Human Behaviour Study - ESSHBS 2018 Copyright (C) Institute of Research Engineers and Doctors, USA. All rights reserved.

ISBN: 978-1-63248-156-6 doi: 10.15224/978-1-63248-156-6-18

TABLE II. THE AVERAGE VALUES OF INCREMENTS OF GDP OF THE REGIONS FOLLOWING THE SOLUTIONS OF THE $11 P R_{I}$ PROBLEMS

\begin{tabular}{|c|c|c|c|c|c|c|c|c|c|}
\hline \multirow[t]{2}{*}{ Problem } & \multicolumn{9}{|c|}{ Region } \\
\hline & $r=1$ & $r=2$ & $r=3$ & $r=4$ & $r=5$ & $r=6$ & $r=7$ & $r=8$ & $r=9$ \\
\hline$P r_{1}$ & 0.96 & 0.00 & 0.01 & 0.00 & 0.00 & 0.00 & 0.00 & 0.00 & 0.00 \\
\hline $\mathrm{Pr}_{2}$ & 0.05 & 1.81 & 0.47 & 0.92 & 0.09 & 0.00 & 0.00 & 0.00 & 0.00 \\
\hline $\mathrm{Pr}_{3}$ & 0.01 & 0.01 & 1.12 & 0.01 & 0.00 & 0.00 & 0.00 & 0.00 & 0.00 \\
\hline$P r_{4}$ & 0.00 & 0.00 & 0.00 & 1.86 & 0.00 & 0.00 & 0.00 & 0.00 & 0.00 \\
\hline$P r_{5}$ & 0.00 & 0.00 & 0.00 & 0.00 & 2.91 & 0.00 & 0.00 & 0.00 & 0.00 \\
\hline$P r_{6}$ & 0.47 & 0.64 & 0.57 & 1.08 & 1.13 & 2.39 & 0.16 & 0.21 & 0.36 \\
\hline$P r_{7}$ & 0.04 & 0.08 & 0.06 & 0.12 & 0.00 & 0.08 & 1.29 & 0.06 & 0.18 \\
\hline$P r_{8}$ & 0.13 & 0.04 & 0.04 & 0.07 & 1.12 & 0.05 & 0.07 & 1.44 & 0.09 \\
\hline$P r_{9}$ & 0.17 & 0.17 & 0.13 & 0.33 & 0.41 & 0.16 & 0.11 & 0.16 & 1.26 \\
\hline$P r_{10}$ & 1.54 & 2.65 & 5.10 & 4.15 & 3.67 & 0.00 & 0.00 & 0.00 & 0.00 \\
\hline$P r_{11}$ & 2.57 & 3.75 & 7.76 & 4.97 & 10.21 & 3.06 & 1.14 & 1.69 & 1.71 \\
\hline
\end{tabular}

TABLE III. INCREMENTS OF THE AVERAGE OUTPUT OF THE FOLLOWING INDUSTRY - AGRICULTURAL, FORESTRY AND FISHERIES OF THE REGIONS AS A RESULT OF SOLVING 11 PROBLEMS $P R_{I}$

\begin{tabular}{|c|c|c|c|c|c|c|c|c|c|}
\hline \multirow[t]{2}{*}{ Problem } & \multicolumn{9}{|c|}{ Region } \\
\hline & $r=1$ & $r=2$ & $r=3$ & $r=4$ & $r=5$ & $r=6$ & $r=7$ & $r=8$ & $r=9$ \\
\hline$P r_{1}$ & 6.59 & 0.00 & 0.03 & 0.00 & 1.43 & 0.00 & 0.00 & 0.00 & 0.00 \\
\hline $\mathrm{Pr}_{2}$ & 0.06 & 14.58 & 0.94 & 0.98 & 1.26 & 0.01 & 0.01 & 0.00 & -0.01 \\
\hline $\mathrm{Pr}_{3}$ & 0.01 & 0.02 & 9.00 & 0.01 & 1.56 & 0.00 & 0.00 & 0.00 & 0.00 \\
\hline $\mathrm{Pr}_{4}$ & 0.01 & 0.00 & 0.00 & 5.35 & 0.01 & 0.00 & 0.00 & 0.00 & 0.00 \\
\hline $\mathrm{Pr}_{5}$ & 0.01 & 0.00 & 0.01 & 0.00 & 1.84 & 0.00 & 0.00 & 0.00 & 0.00 \\
\hline $\operatorname{Pr}_{6}$ & 0.79 & 0.66 & 0.98 & 1.44 & 2.47 & 12.62 & 0.62 & 0.35 & 0.71 \\
\hline $\mathrm{Pr}_{7}$ & 0.08 & 0.12 & 0.17 & 0.11 & 1.31 & 0.20 & 11.75 & 0.12 & 0.21 \\
\hline $\mathrm{Pr}_{8}$ & 0.12 & 0.13 & 0.05 & 0.05 & 2.20 & 0.07 & 0.43 & 14.34 & 0.23 \\
\hline $\mathrm{Pr}_{9}$ & 0.29 & 0.38 & 0.23 & 0.32 & 1.59 & 0.21 & 0.56 & 0.15 & 9.46 \\
\hline$P r_{10}$ & 5.59 & 12.37 & 13.52 & 5.36 & 2.09 & 0.01 & 0.01 & 0.00 & -0.01 \\
\hline$P r_{11}$ & 5.75 & 10.28 & 18.36 & 7.48 & 8.66 & 18.07 & 12.74 & 14.99 & 9.00 \\
\hline
\end{tabular}

\section{References}

[1] B. Moro and V. Beker, "Modern Financial Crises. Argentina, United States and Europe," Cham, Heidelberg, New York, Dordrecht, London: Springer, 2016.

[2] D. Acemoglu, "Introduction to modern economic growth," Princeton: Princeton Univ. Press, 2009.

[3] M. Blejer and K.Y. Chu, "Fiscal Policy, Stabilization and Growth in Developing Countries", Ed. M. Blejer and K.Y. Chu, International Monetary Fund, 1989.

[4] S. Rosen, B. Meade, and A. Murray, "International Food Security Assessment, 2015-2025," United States Department of Agriculture: Economic Research Service, 2015.

[5] K. Farmer and M. Schelnast, "Growth and International Trade. An Introduction to the Overlapping Generations Approach," Springer Science \& Business Media, 2013.

[6] P.A Samuelson and W.D. Nordhaus, "Economics 19th Edition," New York: McGraw-Hill/Irwin, 2010; McConnell C.R, Brue S.L., Flynn S.M., Economics, 18th Edition New York, NY: McGraw-Hill Irwin, 2009.

[7] A. Ashimov, B. Sultanov, Zh. Adilov, Yu. Borovskiy, D. Novikov, A. Alshanov, and As. Ashimov, "Macroeconomic analysis and parametrical control of a national economy," New York: Springer, 2013.

[8] GLOBE CGE Model, www.cgemod.org.uk/globe1.html

[9] GAMS, www.gams.com

[10] M. Ferris and T Munson, PATH 4.7, http://www.gams.com/latest/docs/solvers/path/index.html

[11] GTAP Data Base, www.gtap.agecon.purdue.edu/databases/default.asp

[12] World Input-Output Database, http://www.wiod.org/home

[13] World Integrated Trade Solution, http://wits.worldbank.org

[14] World Economic Outlook Databases, http://www.imf.org/external/ns/cs.aspx?id=28
[15] A. Ashimov, Zh. Adilov, R. Alshanov, Yu. Borovskiy, and B.Sultanov, "The theory of parametric control of macroeconomic systems and its applications (I)," Advances in Systems Science and Application, vol. 14, No 1, 2014, pp. 1-21

[16] NLPEC, http://www.gams.com/latest/docs/solvers/nlpec/index.html

About Authors:

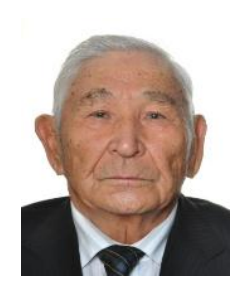

Abdykappar Ashimov - Professor, Doctor of Technical Sciences, Academician of the NAS RK, Research supervisor of the state scientific-technical project

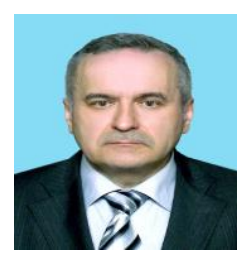

Yuriy Borovskiy - Professor, Candidate of Physical-Mathematical Sciences, Chief research scientist of the state scientifictechnical project

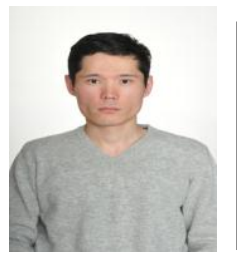

Mukhit Onalbekov - PhD student, Senior researcher of the state scientific-technical project 